\title{
Oceanography Happenings
}

MUCH HAS HAPPENED in our little corner of the world since publication of the December issue of Oceanography. Here, I share a few newsworthy items.

1. Oceanography News. In an effort to timely share important notices with the ocean science community, we now devote a section of The Oceanography Society home page (https://tos.org/) to Oceanography news. A recurring feature in this news section is a listing of early online releases of magazine articles to advertise their availability more prominently. When you next visit the TOS home page, don't forget to scroll down to read the latest Oceanography announcements.

\section{Marine Biodiversity Observation Network: An Observing System for Life in the Sea}

DECEMBER 2021

Oceans Across the Solar System

DECEMBER 2021 SUPPLEMENT

Ocean Observing

MARCH 2022

The Changing Arctic Ocean

MARCH 2022 SUPPLEMENT

New Frontiers in Ocean

Exploration

\section{CALL FOR IDEAS!}

Do you have an idea for a special issue of Oceanography? Please send your suggestions to Editor Ellen Kappel at ekappel@geo-prose.com. volume-22-issue-03-supplement.

3. Ocean Observing Supplement. We observing, sponsored by Ocean Networks Canada, the Partnership for Observation of the Global Ocean, the National Oceanic and Atmospheric Administration's Global Ocean Monitoring and Observing Program, and the US Arctic Research Commission. The objective of this supplement is to widely disseminate information about the many ways in which scientists observe the ocean to improve our understanding of planet Earth and support sustainable management of the ocean and its resources. For the inaugural 2021 supplement, we are aligning the content with the priorities of the UN Decade of Ocean Science for Sustainable Development. If you missed the announcement calling for letters of interest by May 20, rest assured you will have a chance to contribute to future ocean observing supplements. More information is available at https://tos.org/pdfs/ocean-observingsupplement.pdf.

\section{JEDI column in Oceanography. On} page 9 in this issue, readers will find the inaugural column contributed by the TOS Justice, Equity, Diversity, and Inclusion (JEDI) committee, which was formed in late 2020. The committee will use the JEDI column as one vehicle to communicate its activities to the ocean sciences community and beyond. Read their first column to learn about the committee's objectives and ways to engage with its members. We would like to see as many TOS members as possible participate in some way with this important JEDI effort.

\section{Happy spring!} are excited to announce the upcoming December publication of the first annual supplement to Oceanography on ocean

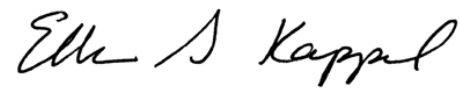

Ellen S. Kappel, Editor 